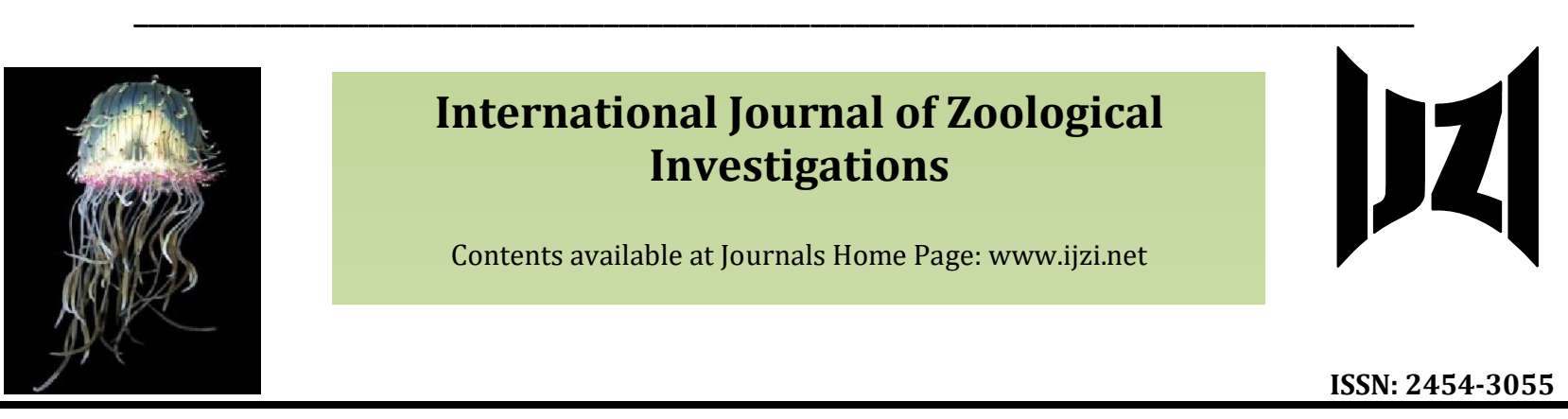

\title{
Prolactin Induced Alterations in Plasma Minerals (Calcium and Phosphate) and Ultimobranchial Gland of Stinging Catfish, Heteropneustes fossilis Maintained in Different Calcium Media
}

\author{
Srivastav Susmita ${ }^{1}$, Mishra Diwakar ${ }^{2}$, Srivastav Sunil K. ${ }^{3}$, Suzuki Nobuo ${ }^{4}$ and Srivastav Ajai K. ${ }^{3^{*}}$ \\ ${ }^{1}$ Department of Zoology, Shiv Harsh Kisan P. G. College, Basti-272001, India \\ 2Department of Zoology, Government Girls' P. G. College, Ghazipur-233001, India \\ 32Department of zoology, D.D.U. Gorakhpur University, Gorakhpur-273009, India \\ ${ }^{4}$ Noto Marine Laboratory, Institute of Nature and Environmental Technology, Kanazawa University, Ogi, Noto-cho, Ishikawa \\ 927-0553, Japan \\ *Corresponding Author
}

Received: $15^{\text {th }}$ October, 2019

Accepted: 28th November, 2019

https://doi.org/10.33745/ijzi.2019.v05i02.008

\begin{abstract}
Effects of prolactin administration were investigated on plasma calcium, and ultimobranchial gland (UBG) of a freshwater catfish, Heteropneustes fossilis. Fish were divided into groups A-D. Group A and B were kept in artificial freshwater with normal electrolytes. Group C and D were maintained in calcium-deficient freshwater. Vehicle was administered to groups A and C. Groups B and D were injected with prolactin. Plasma calcium, inorganic phosphate levels and UBG were studied after 1, 3, 5, 10 and 15 days.

Prolactin treatment caused hypercalcemia from day 3 to day 10; however, the values become narmocalcemic at day 10 and day 15. Similarily, from day 5 onwards a progressive increase in the plasma phosphate level has been noticed.
\end{abstract}

UBG cells of prolactin-treated fish (kept in artificial freshwater) exhibit increased nuclear volume and poor staining response (from day 5 to 10). On day 15 few degenerating cells and a decline in nuclear volume have been noticed.

In vehicle-injected fish (group C) the plasma calcium level decreases from day 1 to day 3 (as compared to level of the fish kept in artificial freshwater). Thereafter, the level records an increase from day 5 resulting in hypercalcemia at day 10 and day 15. In prolactin treated fish (group D) the plasma calcium level shows no change up to day 3 as compared to the vehicle-injected group (group C). From day 5 to day 15, the value indicates progressive increase in plasma calcium level.

The plasma phosphate level of vehicle-injected fish (group C) remains unaltered on day 1. A progressive hypophosphatemia has been observed between day 3 and day 5. Thereafter, the values indicate a tendency to increase. Up to day 3 the plasma phosphate level of prolactin-injected fish (group D) is almost same as compared to that of vehicle-injected specimens (group C). Thereafter, the level indicates a tendency to increase thus resulting in hyperphosphatemia 5 day onwards. 
Up to day 5 there is no change in the ultimobranchial gland of vehicle-injected fish (group C). The staining response of ultimobranchial cells becomes slightly poor at day 10 and day 15 . The nuclear volume of ultimobranchial cells remains unaltered throughout the experiment.

In prolactin-injected fish (group D) the ultimobranchial gland exhibits hyperactivity on day 5 and day 10 which is evident by the increase in the nuclear volume and a decrease in the staining response of the cells. On day 15 , the nuclear volume gets further increased and certain exhausted cells are also seen.

Keywords: Prolactin; Ultimobranchial gland; Plasma calcium; Plasma phosphate ; Fish

Citation: Srivastav Susmita, Mishra Diwakar, Srivastav Sunil K., Suzuki Nobuo and Srivastav Ajai K.: Prolactin induced alterations in plasma minerals (calcium and phosphate) and ultimobranchial gland of stinging catfish, Heteropneustes fossilis maintained in different calcium media. Intern. J. Zool. Invest. 5 (2): 97-107, 2019 https://doi.org/10.33745/ijzi.2019.v05i02.008

\section{Introduction}

The endocrine systems for calcium regulation differ between aquatic and land vertebrates. Fish possess unique and more complex system than the terrestrial vertebrates as they (fish) are in constant contact with surrounding water (either freshwater or seawater) which provides an inexhaustible supply of calcium, thus in most cases facing considerable calcium gradients across the body surface. This situation is very much different in land vertebrates where direct exchanges of calcium between the body and surrounding medium are not possible and they have to rely solely on the food for calcium. In them calcium homeostasis is achieved mainly by a balance between intestinal calcium absorption and renal calcium excretion.

Fish regulate their blood calcium level very efficiently. The regulation of calcium homeostasis in fishes involves a number of hormones secreted by different endocrine glands. Pituitary (through prolactin) takes the responsibility of releasing the hypercalcemic factor (s) in the absence of parathyroid gland (which secretes hypercalcemic principle in land vertebrates). Also vitamin D metabolites have been reported as a hypercalcemic factor in fishes (Srivastav, 1983, 1989; Srivastav and
Srivastav, 1988; Srivastav and Singh, 1989, 1992; Srivastav et al., 1995, 1998). In fishes, the hypocalcemic factors are released conjointly from the ultimobranchial gland (UBG) and the corpuscles of Stannius (CS) (which is found only in this group). Thus, in fishes calcium homeostasis is governed by the pituitary, ultimobranchial gland, corpuscles of Stannius and vitamin D metabolites. The interplay of the hormones released by these endocrine glands at various target organs (skin, fin, gut, gill, bone, kidney) is responsible for fish calcium homeostasis.

Formerly, it was believed that the ultimobranchial gland might be the teleostean equivalent of parathyroid gland (Rasquin and Rosenbloom, 1954). Later, this hypothesis was shown to be inaccurate and at present, the UBG in fishes is homologous with the calcitonin cells of mammals and calcitonin has been demonstrated in the ultimobranchials of a number of fish species (McMillan et al., 1976; Robertson, 1986; Copp and Kline, 1989; Sasayama et al., 2001).

The absence of parathyroid gland in fishes stimulated the search for the hypercalcemic endocrine factor in this group. Several studies have indicated the pituitary gland as the endocrine organ responsible for the release of 
the hypercalcemic factor, with prolactin as the active principle.

The pituitary gland of teleost has been implicated in calcium regulation since 1956 when Fontaine found that removal of the pituitary of freshwater eels caused hypocalcemia. That the pituitary factors involve is prolactin have been suspected since Pang et al. (1973) found that hypophysectomized killifish Fundulus heteroclitus adapted to calcium-deficient seawater showed hypocalcemia as tetanic seizures. These effects could be corrected by administration of pituitary homogenates of mammalian prolactin (Pang, 1981). Other studies have also shown that mammalian prolactin is hypercalcemic in a variety of teleost fishes (Flik et al., 1984, 1986 b; Hasegawa et al., 1986; Fargher and McKeown, 1989; Wendelaar Bonga and Pang, 1991; Kumar et al., 2019).

Teleost is the earliest extant vertebrate group possessing true bone tissue. Bone shows a high degree of variation within this group regarding the organization of the bone matrix. Irrespective of matrix organization, teleost bone can be divided into cellular and acellular bone, the latter being defined as bone which lacks osteocytes (Moss, 1961). Despite the somewhat misleading name, acellular bones does contain the other cell types present in cellular bone i.e. osteoblasts, osteoclasts and bone lining cells. Acellular bone is unique for teleost fish, whereas teleosts cellular bone is homologous to the bone of later vertebrates and the question whether or not acellular bone is a primitive or an advanced character has been a subject of much debate.
Acellular bone was long considered to function as a "sink" for minerals, lacking both osteocytes and osteoclasts. Once deposited, calcium could not be withdrawn from the bone. Thus, it was believed that acellular bone did not participate in active calcium turnover in the body (Moss, 1962; Simmons, 1971). However, the presence of osteoclasts and the ability of these cells to resorb acellular bone have been demonstrated under various physiological and experimental conditions, and there is no doubt that acellular bone participates in the calcium turnover of the body (Weiss and Watabe, 1979; Glowacki et al., 1986; Sire et al., 1990; Takagi and Yamada, 1992).

With this background an attempt has been made in the present study to investigate the effects of prolactin administration in the catfish, Heteropneustes fossilis maintained either in artificial freshwater or calciumdeficient freshwater. The changes induced experimentally by this hormone in the plasma calcium and phosphate levels have been correlated with the activity of ultimobranchial gland cells.

\section{Materials and Methods}

Live specimens of stinging catfish, Heteropneustes fossilis (both sexes; body wt. 23-34 g) were collected locally and acclimatized to laboratory conditions for two weeks in plastic pools. The water was half renewed daily and the fish were fed on dry shrimp powder on alternate days.

For experiments the fish were kept in identical glass aquaria each containing 10 litres of the medium. 12 fish were kept in each aquarium. The medium was replaced on alternate days. To avoid the effects of 
circadian rhythm the injections were administered at the same hour of the day (between 8.00 a.m. and 9.00 a.m.). The Ethical Committee of Department of Zoology, DDU Gorakhpur University, approved all the experimental protocols. Fish were not fed 24 $\mathrm{h}$ before and during the experiment.

\section{Preparation of artificial media:}

Different artificial media i.e. freshwater, calcium-deficient and calcium-rich freshwater were prepared as follows:

(a) Artificial freshwater: Distilled water containing (in mmol/liter): $\mathrm{NaCl} 2.10 ; \mathrm{Na}_{2} \mathrm{SO}_{4}$ $0.45 ; \mathrm{KCl} 0.06 ; \mathrm{CaCl}_{2} 0.8 ; \mathrm{MgCl}_{2} 0.20$. $\mathrm{pH}$ of the solution was adjusted to 7.6 with $\mathrm{NaHCO}_{3}$.

(b) Calcium-deficient freshwater: same as above without $\mathrm{CaCl}_{2}$.

\section{Experimental designs:}

Adult fish Heteropneustes fossilis (both sexes; body wt 24-37 g) were obtained, acclimatized and divided into 4 numerically equal groups each containing 50 fishes. They were given following treatments:

Group A: Fish were maintained in artificial freshwater and were daily injected intraperitoneally daily with vehicle $(0.1 \mathrm{ml}$ of $0.6 \% \mathrm{NaCl} / 100 \mathrm{~g}$ body wt).

Group B: Fish were kept in artificial freshwater and were daily injected intraperitoneally with $0.1 \mathrm{mg} / 100 \mathrm{~g}$ body wt of Prolactin.

Group C: Fish were maintained in calciumdeficient freshwater and were daily injected intraperitoneally with vehicle.

Group D: Fish were kept in calcium-deficient freshwater and were daily injected intraperitoneally with $0.1 \mathrm{mg} / 100 \mathrm{~g}$ body wt of Prolactin.
Prolactin used in groups B and D was dissolved in $0.6 \% \mathrm{NaCl}$ solution. Ten fish from each group were anaesthetized with MS 222 and blood samples were taken $2 \mathrm{hr}$ after the last injection on 1, 3, 5, 10 and 15 days of the treatment.

\section{Technical procedures:}

(i) Mineral determinations with plasma: Blood samples were collected in heparinized tubes by sectioning of the caudal peduncle. The plasma were separated by centrifugation and analysed for calcium and phosphate levels by Sigma kits.

\section{(ii) Preparation for histological studies:}

After collection of blood samples, the area adjoining the heart along with the oesophagus were removed and fixed in aqueous Bouin's fluid. Tissues were routinely processed in graded series of alcohols, cleared in xylene and embedded in paraffin. Serial sections were cut at $6 \mu \mathrm{m}$. Ultimobranchial glands were stained with hematoxylin-eosin (HE).

(iii) Nuclear volume: Nuclear (UBG cells) indexes (maximal length and maximal width) were taken with the aid of ocular micrometer and then nuclear volume was calculated as --

$$
\text { Volume }=4 / 3 \pi \mathrm{ab}^{2}
$$

Where ' $a$ ' is the major semiaxis and ' $b$ ' is the minor semiaxis.

(iv) Statistical analysis: All data were presented as the mean \pm S.E. of six specimens and Student's $t$ test was used to determine statistical significance. In all cases the experimental group was compared to its specific time control group.

\section{Results}

(A) Artificial freshwater (groups A and B): 


\section{Plasma calcium and phosphate:}

No change has been noticed in the plasma calcium levels of vehicle-injected specimens (group A; Fig. 1) throughout the experiment.

Following prolactin treatment (group B) the plasma calcium levels remain unaffected on day 1. From day 3 to day 5 the levels progressively increased. The values become normocalcemic at day 10 and day 15 (Fig. 1).
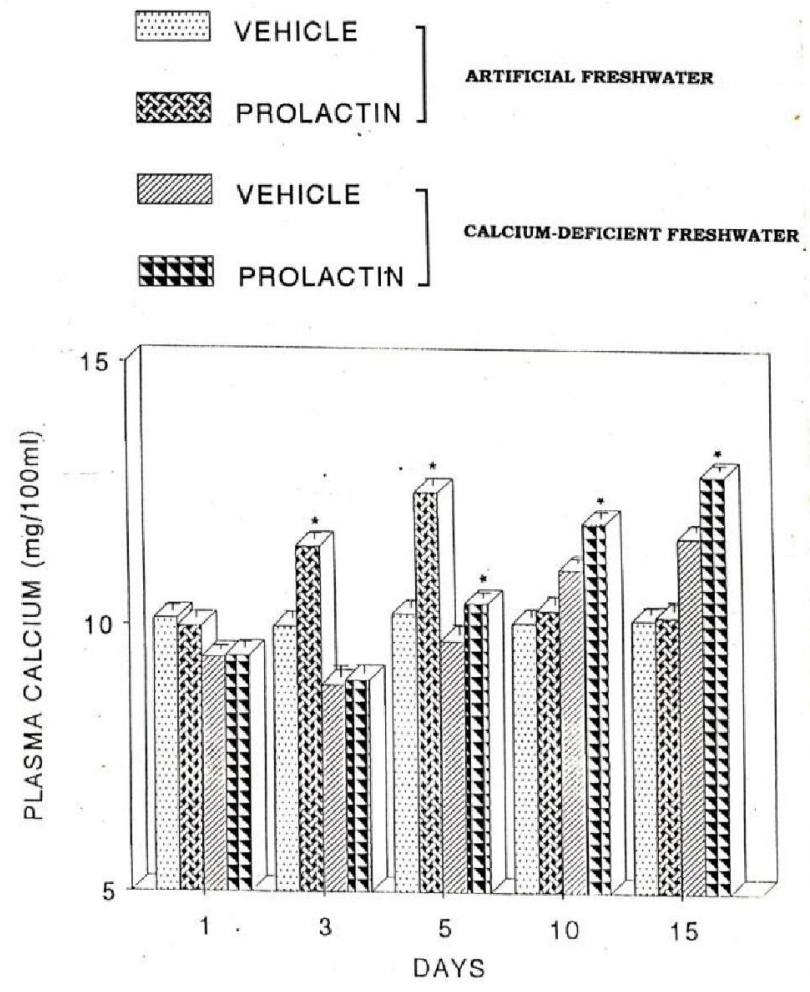

Fig. 1: Changes in the plasma calcium levels of Heteropneustes fossilis kept either in artificial freshwater or calcium-deficient freshwater and treated with vehicle or prolactin. Each value represents mean \pm S.E. of six specimens. Asterisk indicates significant differences $(\mathrm{P}<0.05)$ with vehicle-injected specimens.

The plasma phosphate level of vehicleinjected fish (group A) remains unaltered throughout the experiment (Fig. 2).

Almost no change has been noticed in the plasma phosphate level of prolactin-treated fish (group B) up to day 3 (Fig. 2) as compared to the vehicle-injected specimens (group A). From day 5 onwards a progressive increase in the plasma phosphate level has been noticed (Fig. 2).

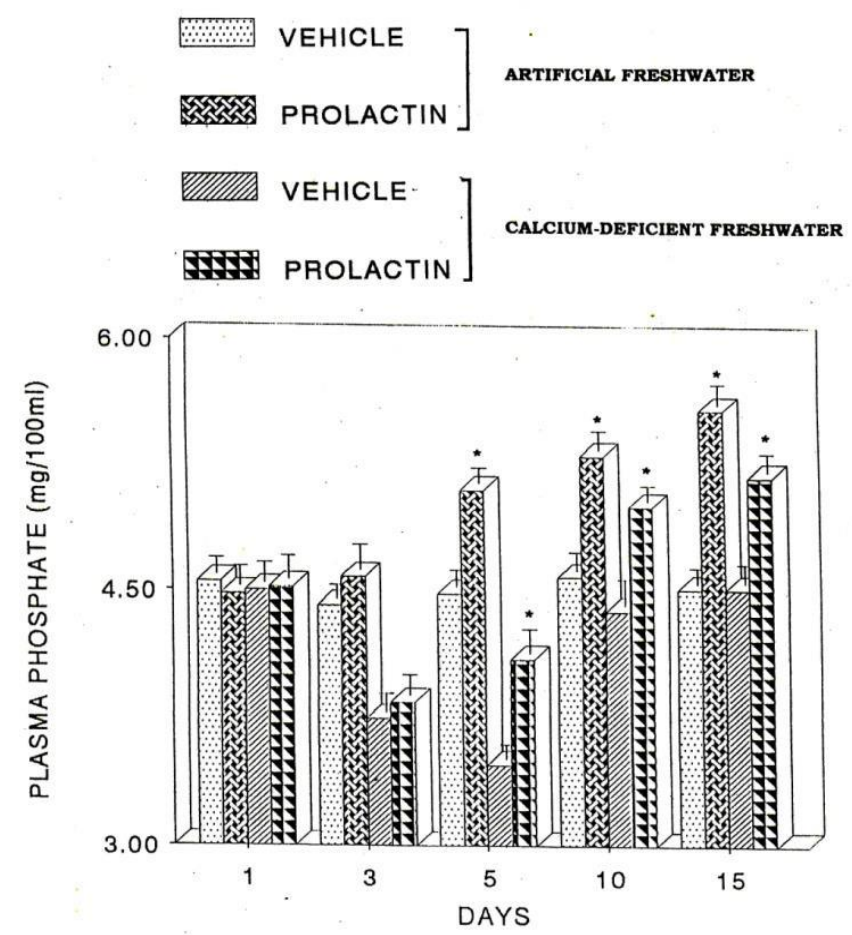

Fig. 2: Changes in the plasma phosphate levels of Heteropneustes fossilis kept either in artificial freshwater or calcium-deficient freshwater and treated with vehicle or prolactin. Each value represents mean \pm S.E. of six specimens. Asterisk indicates significant differences $(\mathrm{P}<0.05)$ with vehicle-injected specimens.

\section{Ultimobranchial gland:}

The histological details of the ultimobranchial gland (Fig. 3) of vehicle-injected fish (group A) are more or less similar to those of the details given for the control fish. The gland depicts no change throughout the experiment.

There is no change in the nuclear volume of ultimobranchial cells of prolactin treated fish (group B) up to day 3. From day 5 to day 10 these cells exhibit increased nuclear volume (Fig. 4) and poor staining response (Fig. 5). On day 15, the nuclear volume 
exhibits a decline (Fig. 4) and a few degenerating cells are noticed (Fig. 6).

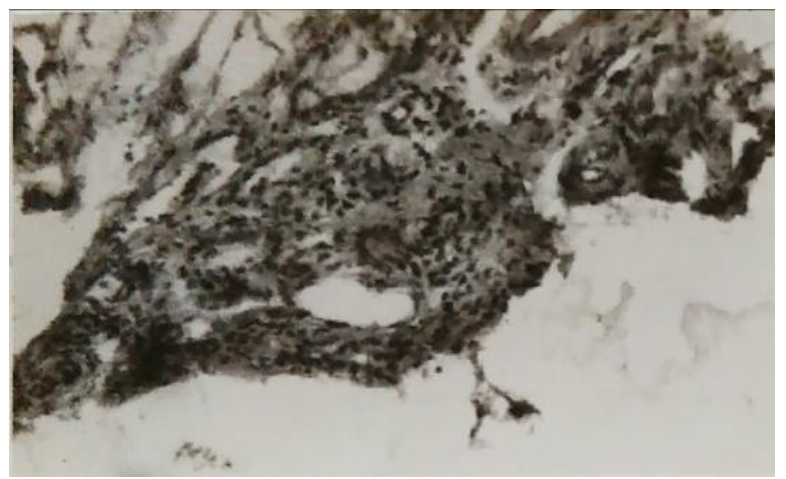

Fig. 3: Ultimobranchial gland of 5 day vehicle-injected Heteropneustes fossilis kept in artificial freshwater showing follicles and cords. HE x 200.
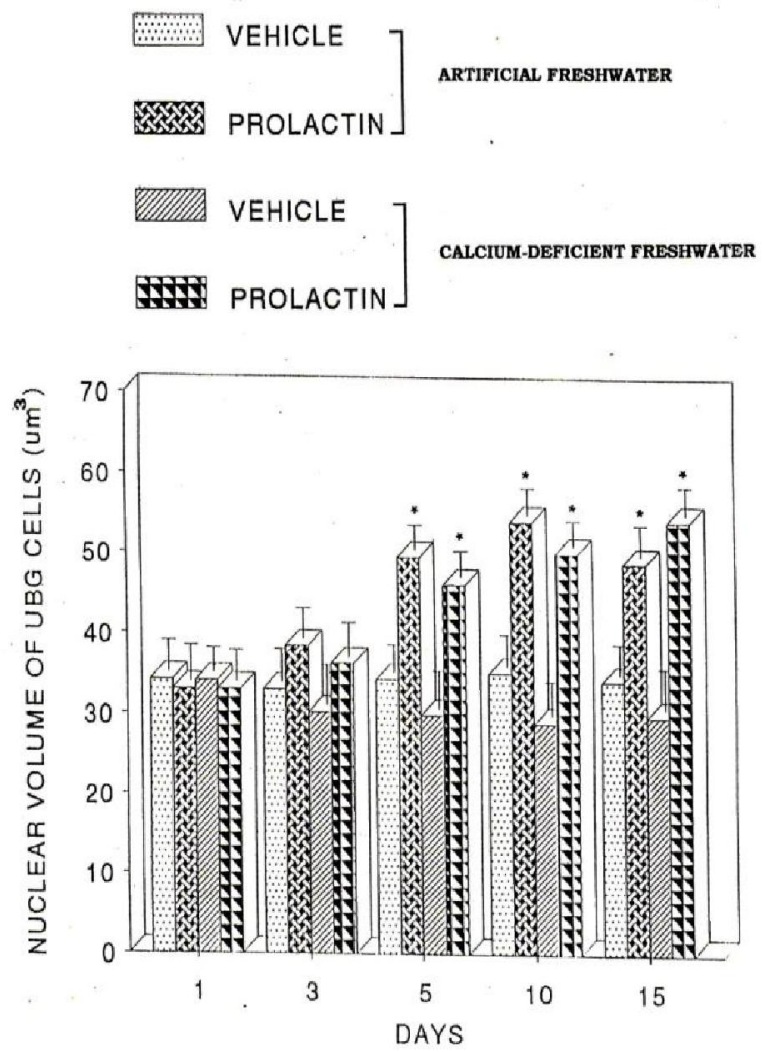

Fig. 4: Nuclear volume of ultimobranchial gland of Heteropneustes fossilis kept either in artificial freshwater or calcium-deficient freshwater and treated with vehicle or prolactin. Each value represents mean \pm S.E. of six specimens. Asterisk indicates significant differences $(\mathrm{P}<0.05)$ with vehicleinjected specimens.

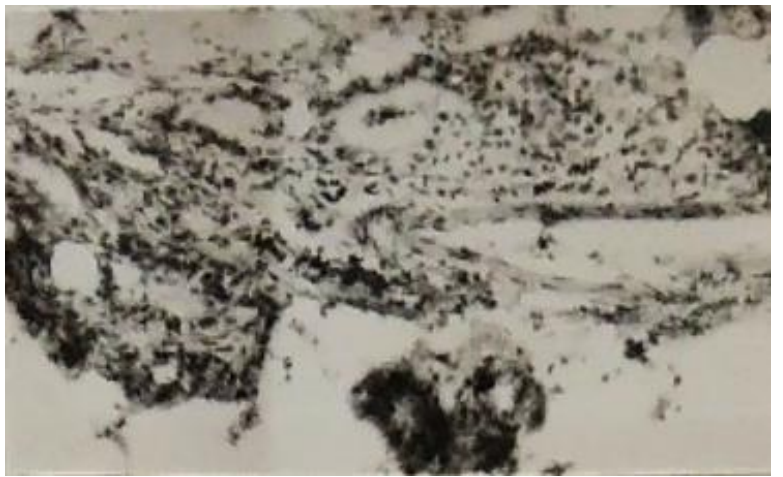

Fig. 5: Ultimobranchial gland of 10 day prolactin treated fish kept in artificial freshwater exhibiting poor staining response. HE x 200.

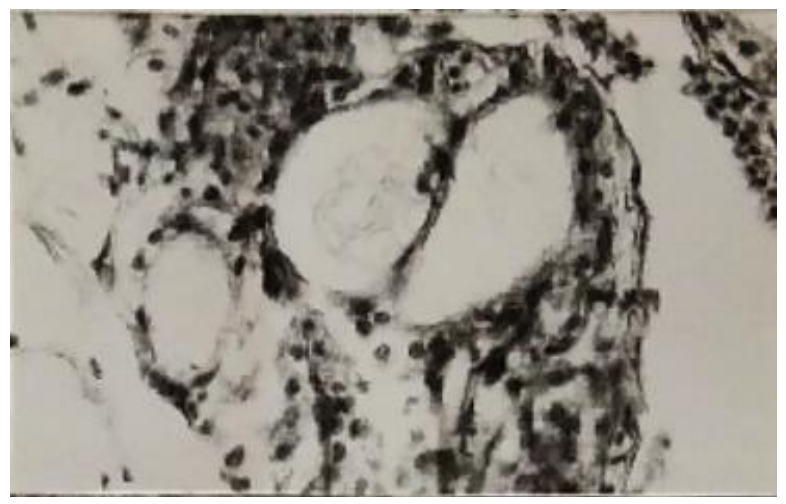

Fig. 6: Degenerating cells in the ultimobranchial gland of 15 days prolactin treated fish maintained in artificial freshwater. HE x 200.

(B) Calcium-Deficient freshwater (groups $C$ and D):

Plasma calcium and phosphate:

In vehicle-injected fish (group C) the plasma calcium level decreases from day 1 to day 3 (as compared to level of the fish kept in artificial freshwater). Thereafter, the level records an increase from day 5 resulting in hypercalcemia at day 10 and day 15 (Fig. 1).

In prolactin treated fish (group D) the plasma calcium level shows no change up to day 3 as compared to the vehicle-injected group (group C). From day 5 to day 15, the value indicates progressive increase in plasma calcium level (Fig. 1). 
The plasma phosphate level of vehicleinjected fish (group C) remains unaltered on day 1. A progressive hypophosphatemia has been observed between day 3 and day 5 . Thereafter, the values indicate a tendency to increase (Fig. 2).

Up to day 3 the plasma phosphate level of prolactin-injected fish (group D) is almost same as compared to that of vehicle-injected specimens (group C). Thereafter, the level indicates a tendency to increase thus resulting in hyperphosphatemia 5 day onwards (Fig. 2).

\section{Ultimobranchial gland:}

Up to day 5 there is no change in the ultimobranchial gland of vehicle-injected fish (group C). The staining response of ultimobranchial cells becomes slightly poor at day 10 and day 15 (Fig. 7). The nuclear volume of ultimobranchial cells remains unaltered throughout the experiment (Fig. 4).

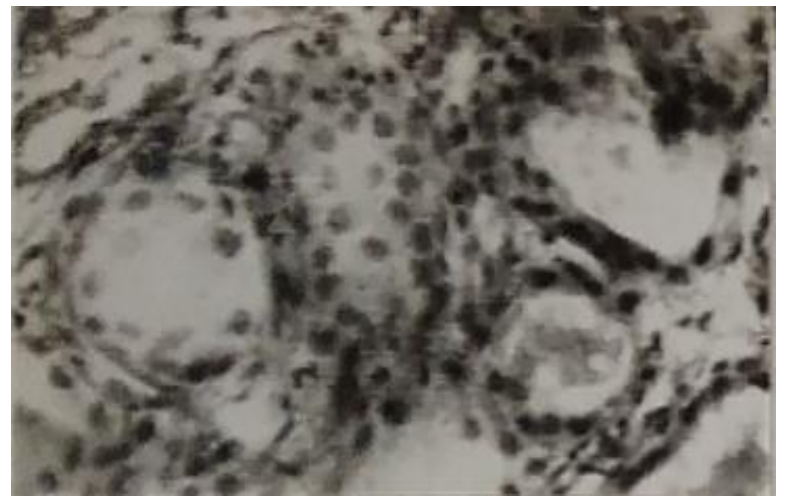

Fig. 7: Ultimobranchial gland of 15 days vehicleinjected fish kept in calcium-deficient freshwater showing decrease staining response of cytoplasm. HE x 200.

In prolactin-injected fish (group D) the ultimobranchial gland exhibits hyperactivity on day 5 and day 10 which is evident by the increase in the nuclear volume (Fig. 4) and a decrease in the staining response of the cells (Fig. 8). On day 15, the nuclear volume gets further increased (Fig. 4) and certain exhausted cells are also seen (Fig. 9).

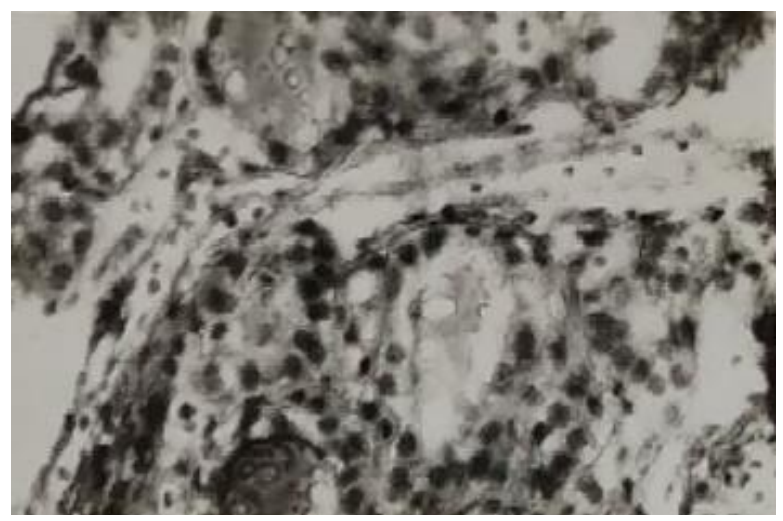

Fig. 8: Ultimobranchial gland of 10 day prolactin treated Heteropneustes fossilis kept in calciumdeficient freshwater depicting decreased staining response of the cytoplasm. HE x 200 .

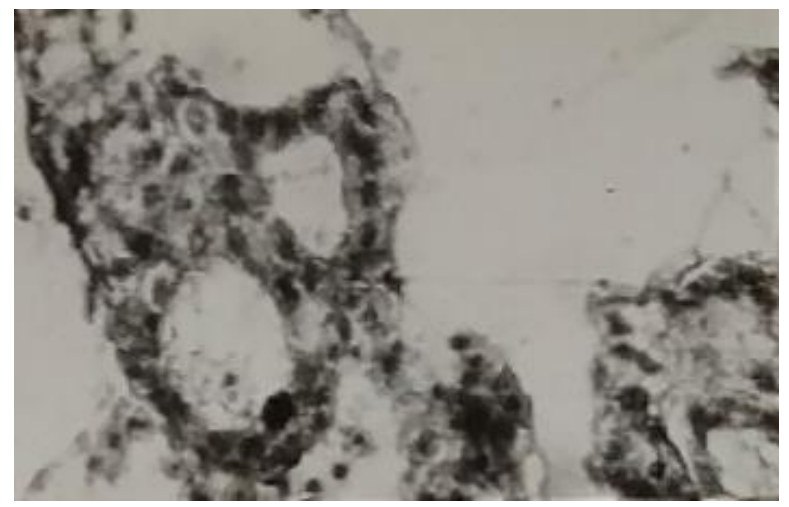

Fig. 9: Exhausted cells in the ultimobranchial gland of 15 day prolactin treated fish maintained in calciumdeficient freshwater. HE x 200.

\section{Discussion}

Administration of prolactin to $H$. fossilis kept either in artificial freshwater or calciumdeficient freshwater provoked hypercalcemia and hyperphosphatemia. The hypercalcemic action of prolactin has been confirmed for a variety of teleosts (Flik et al., 1984, 1986 a, 1994; Hasegawa et al., 1986; Fargher and McKeown, 1989; Chakraborti and Mukherjee, 1995). The present study derives support from the observed hypocalcemia in hypophysectomized teleost (Pang et al., 1978; 
Pang, 1981; Mugiya and Odawara, 1988). The observed hypercalcemia in prolactin administered $H$. fossilis kept in calcium deficient freshwater cannot be attributed to the utilization of environmental calcium by the fish as calcium is not present in the medium. Also as the fish were not fed in the present study prolactin induced hypercalcemia may not be linked to increased intestinal calcium uptake. The possible cause for the hypercalcemia and hyperphosphatemia in prolactin-injected $\mathrm{H}$. fossilis may be the increased reabsorption of calcium and phosphate by the kidney and/or increased resorption of bones.

In vehicle-injected fish kept in calciumdeficient freshwater the plasma calcium and phosphate levels decreased. Hypocalcemia has also been recorded in tilapia after 5 days of its transference to low ambient calcium (Wendelaar Bonga et al., 1984). This can be attributed to the increased efflux of $\mathrm{Ca}^{++}$ through gill. Flik et al. (1986 a) have suggested that low calcium concentration in the ambient water of tilapia would allow intracellular $\mathrm{Ca}^{++}$ to diffuse out of the animal. Branchial efflux routes of $\mathrm{Ca}^{++}$following paracellular routes could be increased as a result of lower ambient $\mathrm{Ca}^{++}$. The observed hypocalcemia may also be explained on the basis of increased integumental water permeability at low ambient $\mathrm{Ca}^{++}$as observed by Wendelaar Bonga and Van Der Meij (1981). Fenwick (1981) has suggested that increased water uptake at low ambient $\mathrm{Ca}^{++}$may increases urine production which leads to $\mathrm{Ca}^{++}$loss from the body.

The plasma calcium is restored and is elevated after day 10 and day 15 in vehicleinjected $H$. fossilis kept in calcium-deficient freshwater. An increase in the plasma calcium content after acclimation of the fish to low ambient calcium/calcium-deficient freshwater has also been recorded by Wendelaar Bonga et al. (1985), Flik et al. (1986 a), Singh and Srivastav (1996) and Srivastav et al. (2002). The present study supports this conclusion as in calcium-deficient freshwater; the prolactin cells of $H$. fossilis became hyperactive. Prolactin has been reported to increase the uptake of $\mathrm{Ca}^{++}$from water in tilapia (Flik et al., 1986 b). In this study calcium is not available in the medium thus; the restoration of calcium can possibly be ascribed to bone demineralization and/or increased mobilization from the soft tissues.

The ultimobranchial gland of $H$. fossilis became hyperactive in response to administration of prolactin to the fish kept either in artificial freshwater or calciumdeficient freshwater. Similar observations about the activity of fish ultimobranchial gland in response to experimental hypercalcemia have been reported in past by several investigators (Lopez et al., 1968; Chan, 1972; Peignoux-Deville et al., 1975; Swarup and Srivastav, 1984; Srivastav et al., 1997, 2002). The studies of Fouchereau-Peron et al. (1986) support the observations of the foregoing study as they have reported that transfer of trout from freshwater to sea water induces the gland to synthesize and secrete more calcitonin which results into a two-fold increase in the plasma calcitonin level.

The ultimobranchial cells of $H$. fossilis depicts a decrease in the staining response after prolactin treatment which is due to the release of increased amount of the hypocalcemic factor (calcitonin) to counteract the hypercalcemia. Similar decrease in the staining response of ultimobranchial cells has also been reported by Swarup and Srivastav 
(1984) and Srivastav et al. (1999). The degeneration of some of these cells may be attributed to the exhaustion in response to continuous hypercalcemic challenge.

The ultimobranchial gland of vehicleinjected $H$. fossilis kept in calcium-deficient freshwater exhibits poor staining response which can be attributed to the observed plasma calcium level.

\section{Acknowledgement}

The authors are thankful to the Head, Department of Zoology, D. D. U. Gorakhpur University, Gorakhpur, India, for providing laboratory facilities for this study.

\section{References}

Chakraborti P and Mukherjee D. (1995) Effects of prolactin and fish pituitary extract on plasma calcium levels in common carp, Cyprinus carpio. Gen. Comp. Endocrinol. 97: 320-326.

Chan DKO. (1972) Hormonal regulation of calcium balance in teleost fish. Gen. Comp. Endocrinol. 3:411-420.

Copp DH and Kline LW. (1989) Calcitonin. In "Vertebrate Endocrinology: Fundamentals and Biomedical Implications", vol. III, (Pang, P.K.T. and Schreibman, M.P., eds.), pp. 79-102. Academic Press, London.

Fargher RC and McKeown BA. (1989) The effect of prolactin on calcium homeostasis on coho salmon (Oncorhynchus kisutch). Gen. Comp. Endocrinol. 73: 398-403.

Fenwick JC. (1981) The renal handling of calcium and renal $\mathrm{Ca}^{2+}\left(\mathrm{Mg}^{2+}\right)$-activated adenosinetriphosphatase activity in freshwater and seawater-acclimated North American eels Anguilla rostrata Le Sueur. Can. J. Zool. 59: 478-485.

Flik G, Fenwick JC, Kolar Z, Mayer-Gostan N and Wendelaar Bonga SE. (1986 a) Effects of low ambient calcium levels on whole body $\mathrm{Ca}^{2+}$ flux rates and internal calcium pools in the freshwater cichlid teleost, (Oreochromis mossambicus). J. Exp. Biol. 120: 249-264.

Flik G, Fenwick JC, Kolar Z, Mayer-Gostan N and Wendelaar Bonga SE. (1986 b) Effects of ovine prolactin on calcium uptake and distribution in the freshwater cichlid teleost fish, Oreochromis mossambicus. Am. J. Physiol. 250: 161-166.

Flik G, Wendelaar Bonga SE and Fenwick JC. (1984) $\mathrm{Ca}^{2}{ }_{+}$-dependent phosphatase and $\mathrm{Ca}^{2}{ }_{+}$-dependent ATPase activities in plasma membranes of eel gill epithelium. II. Evidence for transport high affinity $\mathrm{Ca}^{2+}$-ATPase. Comp. Biochem. Physiol. 79: 9-16.

Fontaine M. (1956) The hormonal control of water and salt electrolyte metabolism in fish. Mem. Soc. Endocrinol. 5: 69-81.

Fouchereau-Peron M, Arlot-Bonnemains Y, Moukhtar MS and Milhaud G. (1986) Adaptation of rainbow trout (Salmo gairdneri) to seawater: changes in calcitonin levels. Comp. Biochem. Physiol. 83A: 8387.

Glowack J, Cox KA, O'Sullivan J, Wilkie D and Deftos LJ. (1986) Osteoclasts can be induced in fish having an acellular bony skeleton. Proc. natl. Acad. Sci. USA 83: 4104-4107.

Hasegawa S, Hirano T and Kawauchi H. (1986) Sodiumrelating activity of chum salmon prolactin in some euryhaline teleosts. Gen. Comp. Endocrinol. 63: 309317.

Kumar A, Srivastav Sunil K and Srivastav Ajai K. (2019) Plasma calcium, phosphate and magnesium levels of the freshwater male stinging catfish, Heteropneustes fossilis in response to hypophysectomy and replacement therapy with prolactin. Intern. J. Zool. Invest. 5: 16-21.

Lopez E, Peignoux-Deville J and Bagot E. (1968) Etude histophysiologique du corps ultimobranchial dun teleosteen, Anguilla anguilla L. au cours d'hypercalcemia experimentales. C.R. Acad. Sci. Paris 267D: 1531-1534.

McMillan PJ, Hooker WM, Roos BA and Deftos LJ. (1976) Ultimobranchial gland of the trout (Salmo gairdneri). I. Immuno-histology and radioimmunoassay of calcitonin. Gen. Comp. Endocrinol. 28: 313319.

Moss ML. (1961) Studies of the acellular bone of teleost fish. Acta Anat. 46: 343-362.

Moss ML. (1962) Studies of the acellular bone of teleost fish. II. Response to fracture under normal and acalcmic conditions. Acta Anat. 48: 337-350.

Mugiya $Y$ and Odawara F. (1988) Effects of hypophysectomy and replacement therapy with ovine prolactin on serum calcium levels and calcification in otoliths and scales in goldfish. Nippon Suisan Gakkaishi 54: 2079-2083.

Pang PKT. (1973) Endocrine control of calcium metabolism in teleosts. Am. Zool. 13: 775-792. 
Pang PKT. (1981) Hypercalcemic effects of ovine prolactin on intact killifish Fundulus heteroclitus, subjected to different environmental calcium challenges. Gen. Comp. Endocrinol. 43: 252-255.

Pang PKT, Pang RK and Sawyer WH. (1973) Effects of environmental calcium and replacement therapy on the killifish, Fundulus heteroclitus after the surgical removal of the corpuscles of Stannius. Endocrinology 93: 705-710.

Pang PKT, Schreibman MP, Balbontin F and Pang RK. (1978) Prolactin and pituitary control of calcium regulation in the killifish, Fundulus heteroclitus. Gen. Comp. Endocrinol. 36: 306-316.

Peignoux-Deville J, Lopez E, Lallier F, Bagot EM and Milet C. (1975) Responses of ultimobranchial body in eels (Anguilla anguilla L.) maintained in seawater and experimentally matured to injections of synthetic salmon calcitonin. Cell Tissue Res. 164: 73-83.

Rasquin P and Rosenbloom L. (1954) Endocrine, imbalance and tissue hyperplasia in teleost maintained in darkness. Bull. Am. Mus. Nat. Hist. 104: 363-425.

Robertson DR. (1986) The ultimobranchial body. In "Vertebrate Endocrinology: Fundamentals and Biomedical Implications", vol. I (Pang, P.K.T. and Schreibman, M.P., eds.), pp. 235-259, Academic Press, London.

Sasayama Y, Takemura M and Takano K. (2001) Ultimobranchial glands in the teleost (Plecoglossus altivelis ryukyuensis): special references to chnages of gland volume in maturation. Okajimas Folia Anat. Jpn. 78: 101-106.

Simmons DJ. (1971) Calcium and skeletal tissue physiology in teleost fishes. Clin. Orthop. Related Res. 76: 244-280.

Singh S and Srivastav Ajai K. (1996) Vitamin $D_{3}$ induced histological changes in the corpuscles of Stannius of a freshwater catfish, Heteropneustes fossilis kept either in artificial freshwater, calciumrich freshwater or calcium-deficient freshwater. Okajimas Folia Anat. Japonica 73: 75-82.

Sire J, Huysseune A and Meunier FJ. (1990) Osteoclasts in teleost fish: Light and electron microscopical observations. Cell Tissue Res. 260: 85-94.

Srivastav Ajai K. (1983) Calcemic responses in the freshwater mud eel Amphipnous cuchia to vitamin $\mathrm{D}_{3}$ administration. J. Fish Biol. 23: 301-303.

Srivastav Ajai K. (1989) Effect of 1,25 dihydroxycholecalciferol administration on prolactin cells of the freshwater catfish Clarias batrachus. Zool. Jb. Physiol. 93: 241-244.
Srivastav Ajai K and Singh Purnima (1989) Response of prolactin cells of the freshwater mjud eel, Amphipnous cuchia to vitamin $\mathrm{D}_{3}$ administration. Zool. Jb. Physiol. 93: 235-240.

Srivastav Ajai K and Singh S. (1992) Effect of vitamin $\mathrm{D}_{3}$ on serum calcium and inorganic phosphate levels of the freshwater catfish, Heteropneustes fossilis, maintained in artificial freshwater, calcium-rich freshwater, and calcium-deficient freshwater. Gen. Comp. Endocrinol. 87: 63-70.

Srivastav Aja K, Singh S and Sasayama Y. (1995) Vitamin $\mathrm{D}_{3}$ induced changes in the prolactin cells of the fish, Heteropneustes fossilis reared in artificial freshwater, calcium-rich freshwater or calcium-deficient freshwater. J. Reproduct. Biol. Comp. Endocrinol. 7: 72-82.

Srivastav Ajai K, Singh Sarita, Srivastav Sunil K and Suzuki Nobuo (1997) Ultimobranchial gland of the catfish, Heteropneustes fossilis treated with vitamin $\mathrm{D}_{3}$ and maintained either in artificial freshwater, calcium-rich freshwater or calcium-deficient freshwater. Asian J. Exp. Sci. 11: 43-53.

Srivastav Ajai K and Srivastav SP. (1988) Corpuscles of Stannius of Clarias batrachus in response to 1,25 dihydroxyvitamin $\mathrm{D}_{3}$ administration. Zool. Sci. 5: 197-200.

Srivastav Ajai K, Tiwari PR, Srivastav SK and Suzuki N. (2002) Responses of the ultimobranchial gland to vitamin $\mathrm{D}_{3}$ treatment in freshwater mud eel, Amphipnous cuchia kept in different calcium environments. Anat. Histol. Embryol. 31: 257-261.

Srivastav Ajai K, Tiwari PR and Suzuki N. (1999) Morphology and histology of ultimobranchial gland of the freshwater mud eel, Amphipnous cuchia. J. Adv. Zool. 20: 17-20.

Srivastav Ajai K, Wendelaar Bonga SE and Flik G. (1998) Plasma calcium and stanniocalcin levels of male tilapia, Oreochromis mossambicus fed with calciumdeficient food and treated with $1,25(\mathrm{OH})_{2} \mathrm{D}_{3}$. Gen. Comp. Endocrinol. 110: 290-294.

Swarup K and Srivastav SP. (1984) Structure and behaviour of ultimobranchial gland in response to vitamin $\mathrm{D}_{3}$ induced hypercalcemia in male Clarias batrachus. Arch. Anat. Microsc. Exp. 73: 223-229.

Takagi I and Yamada K. (1992) effects of calcium deprivation on the metabolism of acellular bone in tilapia, Oreochromis mossambicus. Comp. Biochem. Physiol. 102 A: 481-485.

Wendelaar Bonga SE, Flik G, Lowik CW and Van Eys CJ. (1985) Environmental control of prolactin secretion in the teleost fish Oreochromis (formerly 
Sarotherodon) mossambicus. Gen. Comp. Endocrinol. 57: 352-359.

Wendelaar Bonga SE and Pang PKT. (1991) Control of calcium regulating hormones in the vertebrates: Parathyroid hormone, calcitonin, prolactin and stanniocalcin. Int. Rev. Cytol. 128: 139-213.

Wendelaar Bonga SE and Van der Meij JCA. (1981) Efect of ambient osmolarity and calcium on prolactin cell activity and osmotic water permeability of gills in the teleost Sarotherodon mossambicus. Gen. Comp. Endocrinol. 43: 432-442.

Wendelaar Bonga SE, Van der Meij JCA and Flik G. (1984) Prolactin and acid stress in the teleost Oreochromis (formerly Sarotherodon) mossambicus. Gen. Comp. Endocrinol. 55: 323-332. 